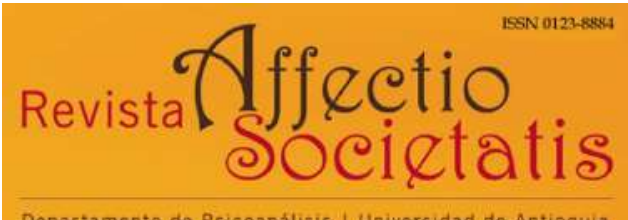

Departamento de Psicoanálisis I Universidad de Antioquia

Revista Affectio Societatis

Departamento de Psicoanálisis

Universidad de Antioquia

revistaaffectiosocietatis@udea.edu.co

ISSN (versión electrónica): 0123-8884

Colombia

2021

Rodrigo Valentín Abínzano, Nicolás Mazal

Las pasiones del ser según Lacan

Revista Affectio Societatis, Vol. 18, N. ${ }^{0}$ 34, enero-junio de 2021

Art. \# 5 (pp. 1-22)

Departamento de Psicoanálisis, Universidad de Antioquia

Medellín, Colombia 
ARTÍCULO DE REFLEXIÓN

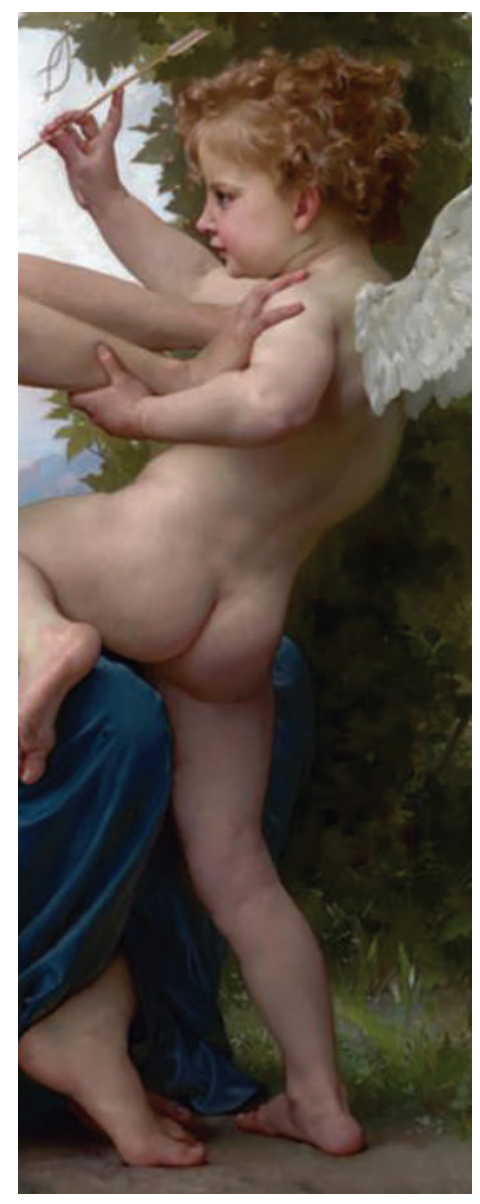




\title{
LAS PASIONES DEL SER SEGÚN LACAN
}

\author{
Rodrigo Valentín Abínzano ${ }^{\top}$ \\ Universidad de Buenos Aires, Argentina \\ abinzanopsi@gmail.com \\ https://orcid.org/0000-0002-7513-9707n
}

\author{
Nicolás Mazal² \\ Universidad Nacional del Alto Uruguay, Argentina \\ nicolasmazal123@gmail.com \\ https://orcid.org/0000-0003-0751-7160
}

DOI: 10.17533/udea.affs.v118n34a04

\section{Resumen}

El presente trabajo explora, localiza lítica y en un segundo lugar se hace y repasa las menciones realizadas por Lacan en el correr de su enseñanza sobre las denominadas "pasiones del ser". Por constituir este un primer abordaje que conforma una investigación más extensa se consideró ubicar inicialmente las menciones acompañadas de los efectos realizados por el rastreo. En primer lugar, se introduce el problema de las pasiones para la clínica psicoanaserie del rastreo al que referimos previamente, contextualizando las referencias y marcando similitudes y diferencias, en vías de generar un movimiento dialéctico entre las mismas. En un apartado final se exponen las conclusiones y las líneas de trabajo ulteriores.

Palabras claves: pasión-ser-odioamor-ignorancia-psicoanálisis

1 Lic. en psicología (UBA). Maestrando en psicoanálisis (UBA). Psicólogo de planta. C.S.M. n³ Arturo Ameghino (CABA). Miembro del Foro Analítico del Río de la Plata (FARP) y de la Escuela de los Foros del Campo Lacaniano. Docente de la Facultad de Psicología (UBA). Autor del libro Lecturas freudianas de la anorexia mental (Escabel, 2018).

2 Lic. en Psicología. (UCA). Especialista en Psicología Clínica con orientación en Psicoanálisis (UBA) (UBA). Magister en Psicoanálisis (Universidad Kennedy). Docente de la Universidad Nacional del Alto Uruguay (Misiones, Argentina). Psicólogo Clínico en el Hospital Escuela de Agudos Dr. Ramón Madariaga (Posadas, Provincia de Misiones, Argentina). 


\section{THE PASSIONS OF BEING ACCORDING TO LACAN}

\section{Abstract}

This paper explores, locates, and reviews the mentions made by Lacan in the course of his teaching about the so-called "passions of being". As this is a first approach that constitutes a more extensive investigation, it was considered to initially locate the mentions accompanied by the effects carried out by tracking. Firstly, the problem of passions for the psychoanalytic clinic is introduced. Then, the tracking we previously mentioned is arranged, contextualizing the references, and marking similarities and differences, in the process of generating a dialectical movement between them. The final section sets forth the conclusions and subsequent lines of work.

Keywords: passion, being, hatred, love, ignorance, psychoanalysis.

\section{LES PASSIONS DE L'ÊTRE SELON LACAN}

\section{Résumé}

Cet article explore, détermine et examine les mentions faites par Lacan sur les dénommées "passions de l'être » au cours de son enseignement. S'agissant d'une première approche encadrée dans une recherche plus approfondie, l'on a décidé de repérer les mentions accompagnées des effets produits par le repérage. Dans un premier temps, l'on a introduit le problème des passions pour la clinique psychanalytique, pour ensuite procéder à un classement de ce repérage en contextualisant les références et en marquant les similitudes et les différences, afin de générer un mouvement dialectique entre celles-ci. Finalement, les conclusions et les pistes de réflexion pour des travaux ultérieurs sont présentées.

Mots clés : passion-être-haine-amour-ignorance-psychanalyse. 


\section{AS PAIXÕES DO SER SEGUNDO LACAN}

\section{Resumo}

O presente trabalho explora, localiza feita uma sequência de rastreamento e revisa as menções realizadas por Lacan no curso do seu ensino sobre as chamadas "paixões do ser". Sendo esta uma primeira abordagem que constitui uma pesquisa mais extensa, foi considerado localizar inicialmente as menções acompanhadas dos efeitos realizados pelo rastreamento. Em primeiro lugar, é introduzido o problema das paixões pela clínica psicanalítica e, em segundo lugar, é ao qual nos referimos anteriormente, contextualizando as referências e marcando semelhanças e diferenças, a fim de gerar um movimento dialético entre elas. Em uma seção final, são apresentadas conclusões e linhas de trabalho subseqüentes.

Palavras-chave: paixão-ser-ódioamor-ignorância-psicanálise

Recibido: 15/12/2020 • Aprobado: 21/3/2021 


\section{Introducción}

El estudio de las pasiones es algo que ha ocupado a la humanidad desde sus comienzos. Ya en el capítulo XXI del Libro V de Metafísica, Aristóteles define al páthos acorde a cuatro puntos: en primer lugar, como "las cualidades en las cuales una cosa puede alterarse"; en segundo término, como "las actividades y las alteraciones de tales cualidades; tercero, las "alteraciones y movimientos que producen daño", especialmente aquellos daños que generan sufrimiento; por último, como "grandes desgracias y sufrimientos" (Aristóteles, 2014, pág. 211).

Más de mil quinientos años después, y ya en la edad moderna, Descartes dedicó sus últimos días a escribir su Tratado de las pasiones del alma donde definía a las pasiones como "percepciones, sentimientos o emociones del alma, que se refieren particularmente a ella, y que son motivadas, mantenidas y amplificadas por algún movimiento de los espíritus" (1981/1649, pág. 166). Además del filósofo francés, San Agustín, Hume y Pascal fueron otros de los nombres propios que tuvieron en consideración a las pasiones en sus elaboraciones. En la enseñanza de Lacan hay que diferenciar dos líneas conceptuales heterogéneas sobre las pasiones: las del alma y las del ser.

Las que conforman el primer grupo son utilizadas por Lacan con asiduidad en su obra escrita, con una marcada diferencia respecto del uso que hace de estas en los seminarios. El libro mencionado de Descartes sobre el tema es evocado en limitadas ocasiones (1961-1962, clase del 17/1/1962; 1965-1966, clase del 5/1/1966), con el objeto de criticar la concepción cartesiana de las pasiones en una supuesta ligazón a la res extensa: "la física de las pasiones del alma está fallada en Descartes, porque ninguna pasión puede ser una afección de la extensión" (Lacan, 1965-1966, clase del 5/1/1966).

Lacan dirá que la brújula del análisis en la vía del sufrimiento en las neurosis y las psicosis es, para nosotros, "la escuela de las pasiones del alma" (2008/1949, pág. 105), y la pasión del alma por excelencia 
para el hombre es "el narcicismo, que impone su estructura a todos sus deseos, aún los más elevados" (2008/1946, pág. 185).

Luego de tener un lugar protagónico en los textos entre 1946 y $1950^{3}$, las pasiones del alma comienzan a ubicarse de modo periférico al momento en que Lacan precisa y reformula la novedad que implican las pasiones del ser. El carácter novedoso del abordaje lacaniano del tema radica en dos cuestiones puntuales: en primer lugar, "destacar la filiación oriental-budista" de las pasiones del ser, y en segundo término, "incluir a la ignorancia", para conformar un ternario (Allouch, 2011, pág. 40). La unidireccionalidad establecida por San Agustín y Pascal entre el amor y el conocimiento encuentra una relaboración en Scheler con la inclusión del odio. El movimiento de subversión lo genera Lacan al introducir la ignorancia, ya que ésta desvincula totalmente conocimiento y ser: "el asunto no es de saber sino de ser y, pasión de la ignorancia obliga, de saber... supuesto" (Allouch, 2011, pág. 41). En ese sentido, la ignorancia del budismo sirvió a las exigencias espirituales orientales para responder al avance de Occidente (Houang, 1981, pág. 252 y sigs.). Lacan señaló en más de una ocasión esta filiación de las pasiones del ser con Oriente (2008/1953, pág. 297; 2012/1969-1970, pág. 144). El dominio de las pasiones del ser es otro que el de las pasiones del alma, ya que es tributario de Oriente y esto establece diferencias.

Como esta es una aproximación preliminar al problema de las pasiones del ser, nuestro objetivo principal será rastrear y ordenar las menciones realizadas por Lacan vinculadas al tema.

Por el lado del ser, la producción de Lacan se vio claramente influenciada por la doctrina de Heidegger (Balmès, 2002), si bien desde su posición antifilosófica afirmaba que con el filósofo oriundo de Messrich compartían una "fraternidad en el decir" (Lacan, 2012/1972, pág. 476). No obstante -y probablemente por ello Balmes en su libro no haga desarrollos en torno de ellas-, las pasiones del ser responden,

3 Mucho tiempo después, encontramos una mención periférica en "Televisión", donde Lacan critica los abordajes que contemplan las pasiones por fuera del lenguaje y habla de una "resección" para las pasiones del alma (2012/1973b, pág. 551). 
como se señaló, a otro afluente conceptual, por lo cual en la producción de Lacan conviven versiones del ser provenientes de Occidente y Oriente. Una complicación especial es que en diversos momentos su delimitación se vuelve harto difusa.

En primer lugar, se tomarán las elaboraciones de Lacan que apunten a un carácter formal o basal de las pasiones del ser, para luego abordar las especificidades planteadas por las mismas al dispositivo analítico. Desde allí, indagaremos especialmente lo que refiere a la demanda. Por último, serán los llamados "afectos posicionales respecto al ser" los que se presentarán más con un carácter de apertura que de cierre, razón por la cual esta investigación dejará planteadas, además de conclusiones, líneas de investigación ulteriores.

\section{Entre el error propio de la existencia y la proximidad al sujeto}

En este primer apartado se repasan y comentan las menciones realizadas por Lacan sobre las pasiones del ser en términos de "forma", "vía de realización" y "advenimiento". Estas menciones tienen un carácter más general, más bien basal, las cuales amortiguan las referencias vinculadas a temas más específicos, como puedan ser el dispositivo analítico, la demanda como operador fundamental y los afectos posicionales.

En "Función y campo de la palabra y del lenguaje en psicoanálisis" (2008/1953), Lacan trae a colación las pasiones del ser con la intensión de ahondar en el carácter erróneo de la existencia, sostenido en la división constitutiva del sujeto:

Pero este misterio se esclarece si se lo enfoca en la fenomenología del sujeto, en cuanto el sujeto se constituye en la búsqueda de la verdad. Basta recurrir a los datos tradicionales que nos proporcionarán los budistas, si bien no son ellos los únicos, para reconocer en esa forma de la transferencia el error propio de la existencia, y bajo tres aspectos que ellos resumen así: el amor, el odio y la ignorancia. Será pues como contraefecto del movimiento analítico como 
comprendemos su equivalencia en lo que suele llamarse una transferencia positiva en el origen, ya que cada uno encuentra la manera de esclarecerse gracias a los dos otros bajo este aspecto existencial, si no se exceptúa al tercero generalmente omitido por su proximidad respecto al sujeto" (pág. 297).

Como se destacó en la introducción, en esta cita se encuentra la filiación de las pasiones del ser en la filosofía budista. Este no es un dato menor, ya que obliga a la tensión y diferenciación con las concepciones occidentales, tanto de la pasión como del ser.

El análisis se presenta como el asilo de la transferencia de origen, donde la existencia aspiraría a un esclarecimiento. Lacan pone énfasis en cómo la ignorancia es la pasión que suele ser dejada de lado por sobre el amor y el odio. En los puntos siguientes de este trabajo veremos que ello es una constante en su argumentación. La hipótesis que ofrece en este momento es que la ignorancia es la pasión más próxima al sujeto. Las pasiones se presentan como anudadas entre sí, y es la transferencia la que permite vislumbrar el error propio de la existencia que encuentra su justificación en el amor, el odio y la ignorancia.

\section{Las pasiones del ser en R.S.I.}

La única correlación topológica de las pasiones del ser con los tres registros se encuentra en Los escritos técnicos de Freud (2009). En ese seminario, Lacan enfatiza la necesidad de introducirse en la Traumdeutung y retomar el operador del Wunsch. Para ello, se vale de dos tipos de sueños: los de deseo y los que denomina "sueño-castigo". El deseo se presenta en el registro del sueño como "el ser que espera revelarse", lo que establece un carácter equivalente: Wunsch para Freud = revelación del ser. Finalmente, Lacan refiere que esto rige para ambos tipos de sueño, diluyendo la división previa. La revelación incide en el pasaje del ser a una nueva etapa, "una nueva encarnación simbólica” (2009/1953-1954, pág. 393). Para abordar la cuestión del ser es presentado un pequeño diamante llamado "diedro de seis caras", el cual exponemos a continuación. 


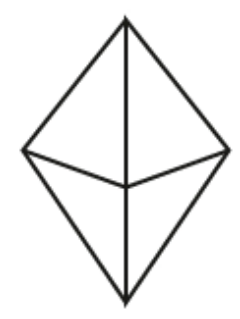

Esta bipirámide triangular no se presenta como un poliedro regular, ya que para serlo cada vértice debe ser concurrido por el mismo número de caras, y la pirámide triangular tiene vértices comunes a tres caras y otros comunes a cuarto caras. En cuanto a la ubicación de los registros, Lacan ubica a lo real en el plano medio, el plano donde se sitúa el triángulo que divide en dos a esta pirámide.

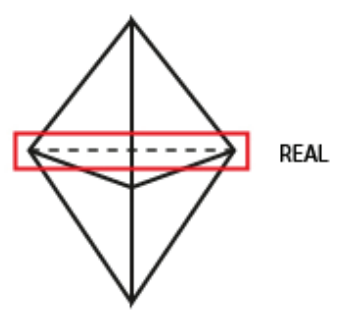

A esto agrega:

Nada de lo que está aquí puede franquearlo, los lugares están ocupados. Pero todo ha cambiado en el otro piso. Porque las palabras, los símbolos introducen un agujero, un hueco, gracias al cual todo tipo de pasajes son posibles. Las cosas se vuelven intercambiables. (2009/1953-1954, pág. 393).

De la cita se puede deducir que cuando Lacan afirma que "nada de lo que está aquí puede franquearlo", ese lugar estaría ubicado en el piso de abajo por el registro de lo imaginario, ya que franquear ese otro lugar es donde se localiza el registro de lo real, ubicado en el plano medio. En el piso de arriba se ubica el registro simbólico, el cual contempla las palabras, los símbolos que introducen un hueco, el cual en lo real posibilita que las cosas se vuelvan intercambiables. La bipirámide con los tres registros se plasmaría del siguiente modo: 


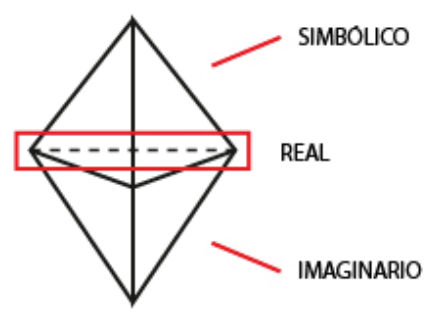

Ese agujero en lo real generado por las palabras y los símbolos -por el registro simbólico- estará ocupado por el ser. Ese ser y esa nada "están vinculados esencialmente al fenómeno de la palabra" (2009/1953-1954, pág. 393) ¿Cómo sería agujerear lo real? Agujereando el modelo de la bipirámide donde está ubicado el ser; ese agujero que introduce lo simbólico en lo real es el lugar del ser.
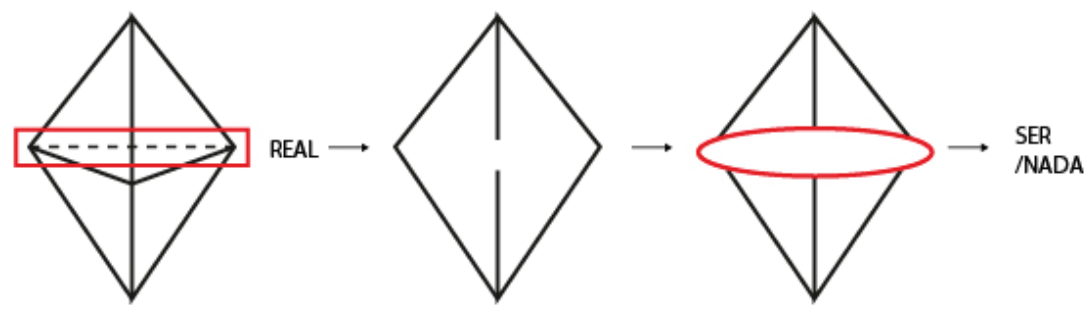

Ahora mostraremos lo que el poliedro intenta mostrar. Lacan refiere que sólo en la dimensión del ser pueden inscribirse las tres pasiones fundamentales: "En la unión entre lo simbólico y lo imaginario, esa ruptura, esa arista que se llama el amor; en la unión entre lo imaginario y lo real, el odio; en la unión entre lo real y lo simbólico, la ignorancia" (2009/1953-1954, pág. 394). Así se articulan las pasiones del ser a los tres registros. Como se expuso previamente, en la unión de lo simbólico e imaginario se ubica esa "ruptura, esa arista" que es el amor; entre lo imaginario y lo real se ubica el odio -cabría preguntarse qué lugar para éste en la "nueva encarnación simbólica-; y por último la unión entre real y simbólico, donde queda situada la ignorancia. Una mostración posible de ellos sería la siguiente:
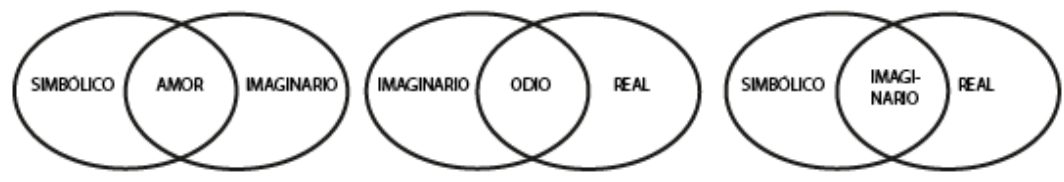
Y desde una aplicación al nudo borromeo, se mostraría de la siguiente manera:

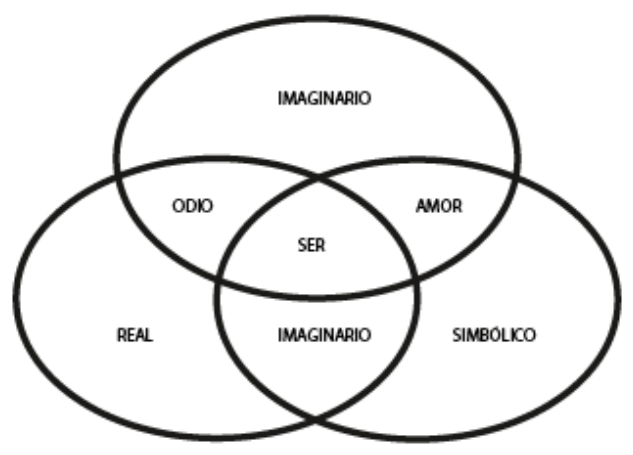

\section{Los confines pasionales de la anorexia mental}

En este apartado tomaremos el paradigma de la mostración de las pasiones del ser que es la anorexia mental. Si bien Lacan trabaja en varios pasajes de su enseñanza tanto las pasiones del ser como la anorexia, el único entrecruzamiento entre ambas tiene lugar al final del escrito "La dirección de la cura y los principios sobre su poder" (2008/1958).

La anorexia presenta su carácter ejemplar -utilidad retórica recurrente en Lacan para con esta-, donde se genera una posibilidad inédita, en términos de claridad sobre la relación entre las pasiones:

Es el niño que alimentan con más amor el que rechaza el alimento y juega con su rechazo como un deseo (anorexia mental).

Confines donde se capta como en ninguna otra parte que el odio es el vuelto del amor, pero donde es la ignorancia la que no se perdona. (2008/1958, pág. 598).

La anorexia permite captar "como en ninguna otra parte" la operatividad del odio como vuelto del amor. La ignorancia se convierte en una pasión imperdonable. El rechazo, en su envoltura lúdica, ho- 
rada la saturación del Otro que ofrece ese "más" de amor. Deseo y rechazo dan cuenta de su equivalencia funcional.

Esa ignorancia que no perdona la anorexia es próxima a la ignorancia crasa, aquella que Lacan en la mayoría de sus versiones aproximó al proceder de los post-freudianos. Dicha ignorancia tiene la estructura de sostenerse en un conocimiento completo, imaginario; de allí la necesidad del rechazo anoréxico de operar simbólicamente, agujereando dicha ilusión de completud.

La referencia que repasamos en el apartado previo presenta un carácter dialógico con ésta en dos puntos: la localización de las pasiones en los registros, el lugar de la nada como operador y antecedente de la falta en ser.

En lo que refiere a la ubicación del odio, el amor y la ignorancia en lo real, imaginario y simbólico, la anorexia presenta la invariante de la relación odio-cuerpo. Si se puede articular con valor de particular las expresiones de odio de las y los anoréxicos en relación con su cuerpo es porque ello parte de una estructura; como se presentó, entre real e imaginario se presenta el odio, y queda por fuera lo simbólico en tanto mediador. Por tomar una referencia clásica, podemos traer a colación al caso de Ellen West, de L. Binswanger: "se entristecía al mirarse al espejo, sintiendo odio contra su cuerpo y golpeándolo con los puños" (1967/1944, pág. 300).
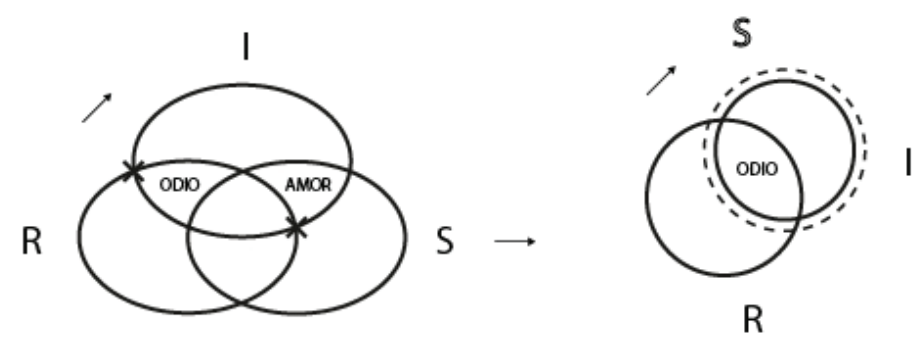

La invariante del cuerpo y el afecto del odio de la anorexia está en correlación estricta con la ignorancia imperdonable -ignorancia cra- 
sa-, y al amor del narcicismo, sin contemplar la vertiente del amor del don; como dijera Lacan: "aprendan a distinguir el amor como pasión imaginaria del don activo que él constituye en el plano simbólico" (2009/1953-1954, pág. 401). Al retomar la disposición que se expuso de los registros en el apartado anterior y en relación con la hipótesis de uno los autores en otra investigación, se puede afirmar que donde lo real avanza sobre lo imaginario, se evidencia la no mediación simbólica (Abínzano y Fernández, 2019)4 .

\section{Homología, ambivalencia y ex-sistencia}

El proceder de Lacan con las pasiones del ser oscila: si bien destaca en más de una ocasión su carácter "homólogo" (2009/1953-1954, pág. 448), también fue manifiesto en señalar que el olvido de la ignorancia hace "imposible" toda práctica analítica (pág. 394), así como que "nada concentra más odio que ese decir donde se sitúa la ex-sistencia" (2010/1972-1973, pág. 147). El amor, al menos en esta versión, es la pasión menos nombrada de las tres, a pesar del mentado carácter homólogo.

En el seminario Aún (2010/1972-1973) y en "Introducción a la edición alemana de los escritos" (2012/1973a), la ignorancia gana cierto terreno por sobre las otras dos pasiones. En lo que refiere al seminario, lo hace en términos de la huella que le deja el lenguaje al saber del ser. Si algo le retorna al sujeto en términos de revelación por la vía del lenguaje es un "saber de más" que es un "no querer saber nada. Pasión por la ignorancia” (2010/1972-1973, pág. 147). En su afán de destacar la relación entre el saber y las pasiones, la ignorancia se presenta como privilegiada, ya que el amor empuja al saber, como sucede con el filósofo que ama el conocimiento porque le tiene horror al saber, y el odio se aproxima como pasión al ex-sistir.

En lo que hace al escrito de 1973, el deseo, que no es lo que empuja al saber, es lo que funda "la pasión mayor del ser hablante, que

4 El gráfico previamente expuesto se extrae de la investigación mencionada. 
no es el amor, ni el odio sino la ignorancia" (2012/1973a, pág. 584). Es retomada y acentuada la necesidad de advertir el lugar de la ignorancia en la matriz del discurso analítico, lo cual se plantea como una vía de entrada por el signo y no por el sentido.

\section{Contra el robot analista}

Desde los comienzos mismos de la práctica analítica se discutió el lugar, la función y los usos de las pasiones en la cura. Si la transferencia como motor y obstáculo es indispensable, los efectos llamados "contratransferenciales" tomaron en algunas perspectivas un lugar tan angular como la transferencia misma.

En lo que refiere a las pasiones del ser, podemos recordar, como se mencionó previamente, que la transferencia da cuenta al sujeto del error de la existencia, y se pueden presentar así las pasiones como modalidades de advenimiento para el ser:

El analista, en efecto, no podría adentrarse en ella sino reconociendo en su saber el sintoma de su ignorancia, y esto en el sentido propiamente analítico de que el síntoma es retorno de lo reprimido en el compromiso, y que la represión aquí como en cualquier otro sitio es censura de la verdad. La ignorancia en efecto no debe entenderse aquí como ausencia de saber, sino, al igual que el amor y el odio, como una pasión del ser; pues puede ser, como ellos, una vía en la que el ser se formá (...) El fruto positivo de la revelación de la ignorancia es el no-saber, que no es negación del saber, sino su forma más elaborada". (Lacan, 2008/1957, pág. 342, énfasis nuestro).

Lacan es claro y consistente al señalar a la ignorancia como "síntoma del saber": como pasión del ser, la ignorancia no importa como ausencia de saber, sino como una vía en la que el ser se forma. El analista también se forma en dichas vías. La forma más elaborada del saber es ese síntoma de la ignorancia, ese "no-saber". Esto es elemental en la formación del analista, ya que en ausencia de este no saber, quien ejerza la práctica del análisis "nunca será otra cosa que un robot analista" (2008/1957, pág. 342). 


\section{De un analista "apasionado" a una posición donde el analista no participa de las pasiones}

Previamente se delimitó que la elaboración de Lacan apuntaba a un analista que esté en relación con las pasiones del ser; inclusive era la vía de escapar a la figura del "robot analista". La ignorancia se erguía, así como la pasión del analista (2008/1958, pág. 569), en tanto síntoma del saber. No obstante, en El reverso del psicoanálisis (2012/1969-1970) este tema es retomado desde una posición diametralmente opuesta:

En su interpelación al pueblo elegido, lo característico de Yahvé es que ignora ferozmente todo cuanto existe, cuando así se manifiesta, sobre ciertas prácticas de las religiones que por entonces abundaban y que se fundaban en cierto tipo de saber, de saber sexual. (...) Simplemente, porque ha existido Yahvé y porque se ha inaugurado cierto discurso que intento aislar este año como reverso del discurso psicoanalítico, a saber, el discurso del amo, a causa de eso precisamente ya no sabemos nada de todo aquello.

¿Es ésta la posición que debe tener el analista? Seguro que no. El analista - ¿llegaré a decir que he podido experimentarlo en mí mismo-, el analista no tiene esta pasión feroz que tanto nos sorprende cuando se trata de Yahvé. Yahvé se sitúa en el punto más paradójico, con respecto a una perspectiva distinta como sería, por ejemplo, la del budismo, que recomienda purificarse de las tres pasiones fundamentales, el amor, el odio y la ignorancia. Lo que más nos cautiva de esta manifestación religiosa única es que a Yahvé no le falta ninguna. Amor, odio e ignorancia, he aquí en todo caso pasiones que no están ausentes en absoluto en su discurso.

Lo que distingue a la posición del analista, y este es el único sentido que se le puede dar a la neutralidad analítica, es que no participa de esas pasiones. (págs. 144-145).

Si establecemos unas sucintas y breves coordenadas contextuales, Lacan se encuentra discutiendo el complejo de Edipo y el padre en Freud en lo que denomina como "el campo del goce". La mención a Yahvé y su feroz ignorancia tiene lugar en dicha secuencia argumental. Una de las cuestiones más importantes a destacar es que esta 
es la única vez que Lacan se refiere a su relación como analista con las pasiones del ser; en este caso puntual con la ignorancia. Hay una toma de posición y distancia de la presencia de las pasiones en el discurso de Yahvé en lo que refiere a una relación de homología con la posición del analista. Vuelve a tener lugar la mención al budismo, al igual que en 1953, como la filosofía que recomendaba una purificación de las pasiones del ser. Lacan excluye al analista de estas pasiones, lo distingue de Yahvé en nombre de la neutralidad. Acorde a este cambio de posición se desprenden algunos interrogantes: ¿Qué implica la purificación de las pasiones? ¿Qué sería no participar de las mismas? ¿Es una advertencia de que las pasiones puedan devenir religiosas? Dejamos estos interrogantes planteados.

\section{La demanda y las pasiones del ser}

En este apartado se retoma el texto "La dirección de la cura..." (Lacan, 2012d) pero con motivo de interrogar las posibles relaciones entre las pasiones del ser y la demanda. Refiere Lacan allí:

El deseo es lo que se manifiesta en el intervalo que cava la demanda más acá de ella misma, en la medida en que el sujeto, al articular la cadena significante, trae a la luz la carencia de ser con el llamado a recibir el complemento del Otro, si el Otro, lugar de la palabra, es también el lugar de la carencia. Lo que de este modo al Otro le es dado colmar, y que es propiamente lo que no tiene, puesto que a él también le falta el ser, es lo que se llama el amor, pero es también el odio y la ignorancia. Es también pasiones del ser, lo que evoca toda la demanda más allá de la necesidad que se articula en ella, y es sin duda aquello de que el sujeto queda privado, tanto más propiamente cuando más satisfecha queda la necesidad articulada en la demanda. (pág. 597).

En el comienzo de la cita, Lacan menciona que "el deseo se manifiesta en el intervalo que cava la demanda...". Son muchos los lugares en que en su enseñanza trabaja la relación demanda y deseo, especialmente en los seminarios Las formaciones del inconsciente (2009/19571958) y El deseo y su interpretación (2014/1958-1959). No obstante, aquí 
se tomará sólo una idea propuesta por Lacan para dicha dialéctica: el deseo no es articulable, sino que es articulado por la demanda. En "Kant con Sade" afirma: "insistamos en que deseo no es sujeto, por no ser en ninguna parte indicable en un significante de la demanda, cualquiera que ella sea, por no ser articulable en ella aun cuando está articulado en ella" (2008/1963, pág. 735).

Si el deseo está articulado a la demanda, y hay una articulación entre demanda y pasiones del ser, indefectiblemente en esta articulación hay que incluir al deseo, "que se articula en el intervalo que cava la demanda más acá de ella misma...". Esa demanda como más acá de ella misma, no es la demanda de satisfacer una necesidad, sino demanda de una presencia o de una ausencia. Si se habla de presencia-ausencia es porque ya está inscripto el registro simbólico. Por lo tanto, no se demanda un objeto de satisfacción, se demanda un objeto simbólico, del cual la madre, como Otro, es poseedora, y que es con lo único que el niño se puede satisfacer. Ese privilegio que le concede el Otro (en este caso la madre) al niño, manifiesta el don de lo que éste no tiene (2008/1958, pág. 658). Además, Lacan refiere que esta demanda es demanda de amor, y que el don es una manifestación de amor. Ambos conceptos, demanda y don, están ligados por una de las pasiones del ser: el amor.

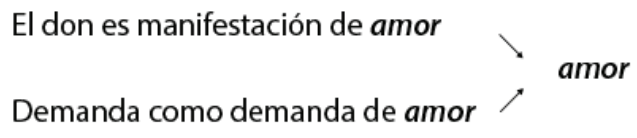

Aquí es donde aparece la primera articulación entre demanda y pasiones del ser, por la vía del amor como punto de ligazón entre demanda y don. Al adicionar la definición de amor: el amor es dar lo que no se tiene, el don y la demanda tendrán otro punto en común con el este.

El don es aquello que manifiesta lo que no se tiene

La demanda es aquello que demanda lo que no se tiene

El amor es dar

lo que no se tiene 
Tanto el don como la demanda están ligados a la definición del amor porque se caracterizan por lo que no se tiene. Si el sujeto demanda amor, es decir, lo que no se tiene, es porque demanda algo que le falta, por lo tanto hay una carencia del ser. Esto que falta es lo que no puede ser articulable, pero sí articulado por la demanda, y es el deseo. El sujeto, a través de una de las pasiones del ser, el amor, demanda lo que no tiene al Otro, es decir, demanda un deseo al Otro. Hasta esta primera instancia la relación entre demanda y pasiones del ser se da en el amor como demanda de amor.

Retomando la cita, Lacan refiere: "en la medida en que el sujeto, al articular la cadena significante, trae a la luz la carencia de ser con el llamado a recibir el complemento del Otro". La articulación de la cadena significante que hace el sujeto en la demanda; cuando el sujeto demanda, por el sólo hecho de hablar, genera una desviación de las necesidades, porque estas ya se encuentran en un mundo inmerso de significantes. Dichas necesidades, que entonces están tomadas por el significante, y por lo tanto sujetas a la demanda, retornan al hombre de manera alienada (2008/1958, pág. 657). ¿Qué quiere decir alienada? Etimológicamente, deriva del latín ălǐēnātǒo, ōnis: alejamiento, privación, procedente a su vez del adjetivo ăliēnus: propio de otro, extraño a uno y ajeno. Con la orientación de este aporte etimológico, si las necesidades que son tomadas por el significante y están sujetas a la demanda retornan alienadas -es decir, que son extrañas a uno, ya que no son suyas, sino del otro, en este caso, del Otro-, entonces la demanda del sujeto sería la demanda del Otro.

En consonancia argumental con lo antes consignado, el deseo no es articulable pero sí articulado por la demanda, ya que cuando el Otro demanda es porque algo le falta, es decir, hay un deseo del Otro. Lacan refiere que la carencia del ser por parte del sujeto expresado en la demanda de amor lo lleva a buscar a que el Otro lo complete, pero "el Otro, lugar de la palabra, es también el lugar de la carencia". Por lo tanto, en el Otro también aparece la carencia del ser, aparece la pasión del amor como demanda de amor, y, como se ha sostenido, si aparece una demanda de amor, en este caso del Otro, es porque allí también hay un deseo articulado por esta demanda. 
Como se ha mencionado previamente, Lacan lo ejemplifica con la anorexia. El Otro, para llenar lo que no tiene, toma al niño y "lo atiborra con la papila asfixiante de lo que tiene, es decir, confunde sus cuidados con el don de amor" (2008/1958, pág. 598). En este caso, el Otro satisface una necesidad y no la demanda del sujeto, demanda que no puede ser satisfecha con la comida, ya que es demanda de amor. Pero el sujeto rechaza ese alimento, y con esto logra no sólo rechazar la demanda del Otro, sino que haya un deseo por fuera de él, es decir, que allí haya un deseo del Otro.

A pesar de que Lacan también menciona las otras dos pasiones del ser, odio e ignorancia, en la cita que se trabajó no se han encontrado prácticamente articulaciones de dichas pasiones con la demanda. La excepción también tiene en un lugar protagónico a la anorexia mental: "Confines donde se capta como en ninguna otra parte que el odio es el vuelto del amor, pero donde es la ignorancia la que no se perdona" (Lacan, 2008/1958, pág. 598). En este sentido, y si bien es considerada una coordenada de apertura para indagar e investigar, la anorexia da cuenta cómo al demandar odio se puede hacer uso del rechazo como mecanismo. Esta referencia, junto con la realizada en el escrito "El psicoanálisis verdadero, y el falso" (2012/1958), funcionan como vías óptimas para profundizar en investigaciones ulteriores.

\section{Afectos posicionales respecto al ser}

En consonancia con lo desarrollado hasta el momento, en la clase del 14 de enero de 1959, en el marco del seminario, se encuentra una mención de particular importancia para esta investigación:

Y el sujeto, ¿qué quiere? Que lo interpretemos.

Interpretar el deseo es restituir aquello a lo cual el sujeto no puede acceder por sí solo, a saber, el afecto que designa su ser y que se sitúa en el nivel del deseo propio. Hablo aquí del deseo preciso que interviene en tal o cual incidente de la vida del sujeto, del deseo masoquista, del deseo suicida, del deseo oblativo, llegado el caso. 
Es cuestión de que esto que se produce bajo una forma inaccesible para el sujeto, recupere su sentido con respecto al discurso oculto que está involucrado en ese deseo, recupere su sentido con respecto al ser, confronte al sujeto con el ser.

Ese sentido auténtico es por ejemplo el que se define por lo que denominaré los afectos posicionales con respecto al ser. Son lo que denominamos mediante estos términos esenciales, amor, odio, ignorancia -pero hay muchos otros cuyo recorrido y cuyo catálogo debemos hacer. (Lacan, 2009/1962-1963, pág. 15, énfasis nuestro).

Esta mención se presenta con un carácter nominal diferente respecto a lo previamente expuesto, ya que Lacan se refiere aquí a las pasiones del ser como "afectos posicionales con respecto al ser", lo cual introduce un matiz con lo dicho de los afectos y el carácter posicional de los mismos. En relación con este último punto, posiblemente se pueda establecer un nexo con la noción de "posiciones subjetivas del ser", elaborada en la última clase de Problemas cruciales para el psicoanálisis (1964-1965, clase del 16/6/1965), donde la posición se articula con tres términos: el sujeto, el saber y el sexo. El afecto que designa al ser del sujeto es aquello restituido por la vía de la interpretación, confrontando al sujeto con el ser, intervención del deseo mediante.

En último término, también es a destacar el hecho de que Lacan no agote estos "afectos posicionales del ser" al amor, el odio y la ignorancia, sino que vehiculiza un imperativo en relación con la confección de un catálogo de los mismos. En ese sentido, es llamativo que no lo vuelve a traer a la colación y que al momento de recurrir a un ejemplar sobre los afectos y las pasiones, redireccione a los interesados al libro II de la Retórica de Aristóteles (Lacan, 2009/1962-1963, pág. 23).

\section{Conclusiones y líneas de investigación ulterior}

El presente trabajo abordó la temática de las pasiones del ser en el marco de la enseñanza de Jacques Lacan. En primera instancia, fueron las menciones referentes a los caracteres formales y de realización del ser, y en un segundo momento se interrogaron las menciones vin- 
culadas al dispositivo analítico, la demanda y la posición del analista. Se indagó especialmente en la demanda y en lo que Lacan denomina "afectos posicionales con respecto al ser". De lo expuesto podemos indicar las siguientes conclusiones y líneas de trabajo ulterior:

a) La diferencia entre las pasiones del ser y las pasiones del alma no se presenta como algo evidente. Probablemente porque en muchos pasajes de la enseñanza de Lacan se plantean de modo difuso, la diferencia filiatoria de unas y otras la inscribe en marcos de referencias distintos. Es necesario precisar dicha confusión.

b) En consonancia con el primer punto, las pasiones del ser no apuntan a un ser en tanto sustancia sino a su vaciamiento. El hecho de que se presenten como "vías de advenimiento o realización" da cuenta de ello.

c) La articulación de los tres registros y las pasiones son una constante que permite, por la vía de formalización topológica, precisar los modos en los cuales la ignorancia, el amor y el odio se articulan en las junturas entre imaginario, real y simbólico.

d) La homología necesaria que se desprende del punto antes señalado encuentra en las elaboraciones de Lacan un cuestionamiento constante. La articulación entre la demanda y el amor como pasión es por la cual se puede orientar dicha equivalencia. No obstante, la posición diferencial de Lacan con la ignorancia es manifiesta en el correr de su obra, y es la pasión que imprime en gran medida a sus desarrollos la originalidad de enfoque sobre el tema.

e) La relación del analista y el ejercicio de su práctica con las pasiones del ser bascula radicalmente. Es necesario profundizar en un abordaje ulterior dichas coordenadas con los interrogantes planteados y precisar la función y uso de las mismas en la cura.

f) La anorexia mental se presenta como el paradigma de la mostración pasional, ya que en la coyuntura por la cual interpela e intenta horadar al Otro mediante el rechazo se evidencia la locación y el efecto de las pasiones.

g) En consonancia con el punto anterior, la demanda de odio en su relación con el rechazo anoréxico es un punto que consideramos menester investigar en un abordaje ulterior. A su vez, el odio tiene un asidero localizable en la clínica de la anorexia mental: el cuerpo. 
h) La posibilidad de ampliación de las pasiones a través del rótulo "afectos posicionales del ser" también apunta a la formalización de un catálogo que contemple otros afectos y/o otras pasiones. También consideramos de importancia indagar en este punto posteriormente.

\section{Referencias}

Abínzano, R. y Fernández, L. (2019). El cuerpo y sus vicisitudes en la anorexia mental: entre el odio y el superyó. Desde el Jardín de Freud. Revista de Psicoanálisis, (19), págs. 117-131. https://revistas.unal.edu.co/index. $\mathrm{php} /$ jardin/article/view/76701/68922

Allouch, J. (2011). El amor Lacan. Cuenco de plata.

Aristóteles. (2014). Metafísica. Gredos.

Balmès, F. (2002). Lo que Lacan dice del ser. Amorrortu.

Binswanger, L. (1967/1944). El caso de Ellen West. En R. May, R. Angel, H. Ellenberger (Comps.), En Existencia. Nueva dimensión en psiquatría y psicología (págs. 288-434). Gredos.

Descartes, R. (1981/1649). Las pasiones del alma. Aguilar.

Houang, F. (1981). La filosofía de la China moderna. La filosofía de Oriente (vol. XI, págs. 226-264). Siglo Veintiuno Editores.

Lacan, J. (1961-1962). Seminario IX: La identificación. Inédito. Versión de R. R. Ponte. Uso interno de la EFBA.

Lacan, J. (1964-1965). Seminario XII. Problemas cruciales para el psicoanálisis. Inédito. Versión de R. R. Ponte. Uso interno de la EFBA .

Lacan, J. (1965-1966). Seminario XIII: El objeto del psicoanálisis. Inédito. Versión de Jorge Tarella. Uso interno de la EFBA.

Lacan, J. (2008/1946). Acerca de la causalidad psíquica de la locura. En Escritos 1 (págs. 151-192). Siglo Veintiuno Editores.

Lacan, J. (2008/1949). El estadio del espejo como formador de la función del yo [je] tal como se nos revela en la experiencia psicoanalítica. En Escritos 1 (págs. 99-106). Siglo Veintiuno Editores.

Lacan, J. (2008/1953). Función y campo de la palabra en psicoanálisis. Escritos 1 (págs. 231-310). Buenos Aires: Siglo Veintiuno Editores.

Lacan, J. (2008/1957). Variantes de la cura-tipo. En Escritos 1 (págs. 311-346). Siglo Veintiuno Editores.

Lacan, J. (2008/1958). La dirección de la cura y los principios de su poder. En Escritos 2. (págs. 559-615). Siglo Veintiuno Editores. 
Lacan, J. (2008/1963). Kant con Sade. En Escritos 2 (págs. 727-754). Siglo Veintiuno Editores.

Lacan, J. (2009/1953-1954). El Seminario, libro 1: Los escritos técnicos de Freud. Paidós.

Lacan, J. (2009/1957-1958). El Seminario, libro 5: Las formaciones del inconsciente. Paidós.

Lacan, J. (2009/1962-1963). El Seminario, libro 10: La angustia. Paidós.

Lacan, J. (2010/1972-1973). El Seminario, libro 20: Aún. Paidós.

Lacan, J. (2012/1958). El psicoanálisis verdadero, y el falso. En Otros escritos (págs. 181-191). Paidós.

Lacan, J. (2012/1969-1970). El Seminario, libro 17: El reverso del psicoanálisis. Paidós.

Lacan, J. (2012/1972). El atolondradicho. En Otros escritos (págs. 473-522). Paidós.

Lacan, J. (2012/1973a). Introducción a la edición alemana de los Escritos. En Otros escritos. (págs. 579-585). Paidós.

Lacan, J. (2012/1973b). Televisión. En Otros escritos (págs. 535-572). Paidós.

Lacan, J. (2014/1958-1959). El Seminario, libro 6: El deseo y su interpretación. Paidós. 